\title{
Laporan pertama infeksi larva Anisakidae pada kerapu merah (Cephalopholis miniata) dari perairan Nusa Tenggara Timur
}

\author{
Aji Winarso \\ Fakultas Kedokteran Hewan, Universitas Nusa Cendana, Kupang, Nusa Tenggara Timur
}

\begin{abstract}
ABSTRAK: Penyediaan pangan asal hewan yang sehat merupakan faktor pendukung dalam pembangunan. Demikian pula dalam penyediaan industri jasa pariwisata yang didalamnya tercakup wisata kuliner. Infeksi larva Anisakidae pada ikan laut yang dikonsumsi harus menjadi perhatian penting dalam penyediaan jasa kuliner makanan laut dari aspek kesehatan masyarakat veteriner. Kajian ini merupakan deskripsi temuan pertama infeksi larva anisakid pada seekor ikan kerapu merah (Cephalopholis miniata). Infeksi larva anisakid pada $C$. miniata ini ditemukan pada peritoneum dan otot perut. Penting bagi masyarakat yang memasak ikan agar memastikan bagian dalam ikan juga matang sempurna agar terhindar dari anisakiasis.
\end{abstract}

\section{Kata kunci:}

anisakiasis, keamanan pangan, parasit ikan, zoonosis

\section{- PENDAHULUAN}

Nusa Tenggara Timur mempunyai potensi akan kekayaan alam lautnya. Nusa Tenggara Timur juga merupakan destinasi pariwisata yang terus berkembang. Kuliner makanan laut (seafood) juga merupakan sajian utama, meliputi berbagai jenis ikan, udang, lobster, kepiting, cumi, dan kerang. Beberapa jenis ikan pada wisata kuliner ditawarkan dalam sajian ikan bakar. Ikan yang sering disajikan sebagai ikan bakar diantaranya adalah kakap, kerapu, dan ikan kaka tua. Mengingat tingkat kematangan ikan bakar akan berbeda pada tiap ketebalannya sehingga penyediaan ikan yang sehat akan menjadi penting. Ikan harus bebas dari infeksi agen food-borne zoonosis, misalnya anisakiasis. Larva anisakis akan mati pada suhu $75^{\circ} \mathrm{C}$ (Raharjo et al. 2017).

Infeksi larva Anisakidae pada ikan laut yang dikonsumsi harus menjadi perhatian penting dalam penyediaan jasa kuliner makanan laut dari aspek kesehatan masyarakat veteriner. Kajian ini bertujuan menjelaskan temuan pertama kasus infeksi larva anisakis pada ikan kerapu merah (Cephalopholis miniata) di Kupang dan potensinya sebagai ancaman kesehatan masyarakat veteriner di lingkungan lahan kering kepulauan Nusa Tenggara Timur.

\section{- BAHAN DAN METODE}

Kajian ini merupakan deskripsi temuan infeksi larva anisakid pada seekor ikan kerapu merah (Cephalopholis miniata). Species ikan kerapu tersebut diidentifikasi berdasarkan Heemstra \& Randall (1993).

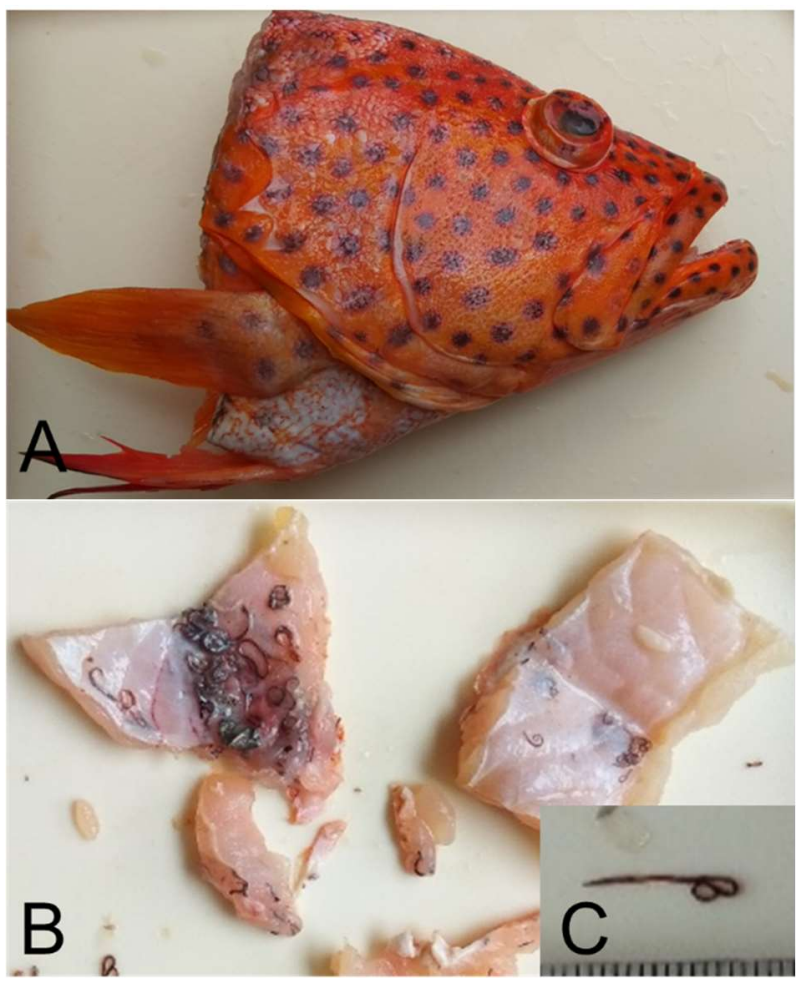

Gambar 1. Kerapu merah (Cephalopholis miniata) dengan temuan larva Anisakid. (A) potongan kepala ikan, (B) larva Anisakidae, dan (C) ukuran individu larva Anisakidae.

\section{- HASIL DAN PEMBAHASAN}

Ikan kerapu (dalam bahasa inggris disebut groupers, rockcods, hinds atau seabasses) mengacu pada kelompok ikan dari family Serranidae. Selain konsumsi dalam negeri, 
kerapu juga merupakan komoditas perikanan tangkap yang di ekspor (Astuti et al. 2016; Agustina et al. 2018). Kerapu merah pada tulisan ini adalah jenis Cephalopholis miniata atau dikenal juga sebagai red coral hind/red coral cod (Gambar 1A). Sebaran C. miniata adalah di perairan indopasifik termasuk Indonesia (Heemstra \& Randall 1993). Ikan C. miniate juga termasuk ikan yang dipasarkan di Ambon dan Maluku (Limmon et al. 2017).

Nekropsi pada ikan kerapu merah ditemukan larva Anisakidae pada peritoneum dan otot perut (Gambar 1B). Infeksi Anisakis pada beberapa species kerapu menunjukkan adanya variasi kepadatan pada beberapa situs utama seperti di hati, otot perut dan rongga perut (Hassan et al. 2013).

Ada tiga genus dari family Anisakidae pada satwa akuatik yang diketahui bersifat zoonotik, yaitu Anisakis, Contracaecum, dan Pseudoterranova (Klimpel \& Palm 2011). Temuan larva anisakis pada kerapu Epinephelus dilaporkan oleh Detha et al. (2018) dan (Paremme et al. 2018). Sedangkan temuan infeksi larva anisakis pada keluarga ikan lain di perairan yang sama yaitu pada cakalang, tongkol (Hibur et al. 2018), kakap merah, kakap putih (Paremme et al. 2018).

Siklus hidup cacing Anisakid dijelaskan secara rinci oleh Klimpel dan Palm (2011). Keterlibatan manusia dalam infeksi zoonotik diilustrasikan oleh CDC (2019). Siklus hidup cacing Anisakid secara umum seperti cacing nematoda, termasuk adanya empat tahapan larva. Anisakidae melibatkan beberapa inang baik invertebrate dan verterbrata, dengan inang akhirnya adalah mamalia laut (Cetacean) (Klimpel \& Palm 2011).

Cacing dewasa hidup di lambung mamalia laut dan cacing betina memproduksi telur anisakid yang keluar ke perairan laut bersama feces inang. Telur tersebut belum berembrio, kemudian embrio berkembang menjadi larva III (L3). Telur berisi L3 kemudian menetas, L3 yang bermantel kutikula (sisa molting dari L2) dapat berenang bebas hingga termakan copepode (Crustacea) (inang antara). Di dalam inang antara tersebut, larva keluar dari mantel dan bermigrasi ke haemocoel dan memulai per-tumbuhan. Inang tersebut membantu perpindahan parasit L3 pada inang antara yang lebih besar, yaitu invertebrata makro (misalnya Cephalopoda). Selanjutnya invertebrata makro membantu infeksi L3 pada ikan (inang paratenik) atau mamalia laut (inang definitif). Melalui predasi, L3 dapat berpindah di antara inang paratenik. Manusia dapat terinfeksi cacing anisakidae setelah mengkonsumsi makan yang ber larva.

Infeksi larva anisakid pada kerapu merah ini terjadi karena kerapu merupakan top level predator pada ekosistem laut (Tucker et al. 2016). Sebagai karnivora, kerapu memakan udang, moluska dan ikan yang lebih kecil (López \& Orvay 2005). Haq et al. (2018) menyebutkan yang biasa dimakan kerapu di antaranya gurita, cumi, keong, remis/kerang, copepoda, ketam, dan ikan. Secara spesifik, Heemstra \& Randall (1993) menyebutkan bahwa $86 \%$ mangsa C. miniata adalah ikan, dan sisanya hampir $14 \%$ adalah copepoda.

\section{- SIMPULAN}

Situs infeksi utama larva anisakid pada ikan kerapu merah (C. miniata) adalah di peritoneum, dan sebagian kecil di otot perut. Penting bagi masyarakat yang memasak ikan agar memastikan bagian dalam ikan telah matang sempurna sebelum dikonsumsi agar terhindar dari anisakiasis.

\section{- INFORMASI PENULIS}

Penulis untuk Korespondensi

*AW: ajiwinarso@staf.undana.ac.id

Fakultas Kedokteran Hewan, Universitas Nusa Cendana, Kupang, Nusa Tenggara Timur. Indonesia.

\section{- PUSTAKA ACUAN}

Agustina LD, Subekti S, Kismiyati. 2018. The prevalence and intensity of gastrointestinal endoparasite worms of cantang grouper (Epinephelus fuscoguttatus-lanceolatus) on floating net cages at Lamong Bay Surabaya, Indonesia. IOP Conf Series: Earth Env Sci. 137: \#012051.

Astuti R, Yonvitner, Kamal MM. 2016. Struktur komunitas ikan kerapu (Serranidae) yang didaratkan di Kecamatan Peukan Bada, Provinsi Aceh. J Ilmu Teknol Kelautan Trop., 8(1): 73-84.

CDC. 2019. Anisakiasis. Tersedia daring: https://www.cdc.gov/dpdx/anisakiasis/index.html [diakses 4 Maret 2020].

Detha AIR, Wuri DA, Almet J, Melky C. 2018. First report of Anisakis sp. in Epinephelus sp. in East Indonesia. JAVAR; 5(1): 88-92.

Hassan MA, Mohamed AMH, Osman HAM. 2013. Some studies on Anisakidae larvae in some marine fish species. Researcher; 5(12): 172-180.

Haq MAB, Srinivasan M, Chandan Tiwary1, S.Vaitheeswari, Kalaiselvi M, Sikder MNA, Min WW. 2018. Food and feeding biology of fish Epinephelus malabaricus of Palk Bay and Gulf of Mannar coastal waters. Intl J Curr Res Multidiscipl.; 1 (7): 12-19.

Heemstra PC, Randall JE. 1993. FAO Species Catalogue, Vol. 16: Groupers of The World. Roma: FAO.

Hibur OS, Detha AIR, Almet J, Irmasuryani. 2016. Tingkat kejadian parasit Anisakis sp. pada ikan cakalang (Katsuwonus pelamis) dan ikan tongkol (Auxis thazard) yang dijual di tempat penjualan ikan Pasir Panjang, Kota Kupang. JKV; 4(2): 40-51

Klimpel S, Palm HW. 2011. Anisakid Nematode (Ascaridoidea) Life Cycles and Distribution: Increasing Zoonotic Potential in the Time of Climate Change? in H. Mehlhorn (ed.), Progress in Parasitology, Parasitology Research Monographs 2. Berlin: Springer.

Limmon GV, Rijoly F, Khouw AS, Manuputty GD, Pattikawa JA. 2017. The Diversity of Grouper (Epinephelinae) in Ambon Island, Maluku, Indonesia. JAP Kagoshima - Occasional Paper \#58. https://www.researchgate.net/publication/320041953.

López VG, Orvay FC. 2005. Food habits of groupers Epinephelus marginatus (Lowe, 1834) and Epinephelus costae (Steindachner, 1878) in the Mediterranean Coast of Spain. Hidrobiológica; 15 (1):27-34.

Paremme AM, Salosso Y, Sunadji. 2018. Identifikasi parasit Anisakis sp pada ikan kakap putih (Lates calcarifer), kakap merah (Lutjanus sanguineus), dan kerapu (Epinephelus sp) yang diperoleh di perairan Teluk Kupang. J Grouper; 9(2): 19-25.

Raharjo HM, Koesdarto S, Estoepangestie ATS, Wardhani KLD. 2017. Preservation effect of grouper (Epinephelus sp) fillet against survival of Anisakidae. In The Veterinary Medicine International Conference 2017, KnE Life Sciences, pp. 10-20.

Tucker SJ, Kurniasih EM, Craig MT. 2016. A new species of grouper (Epinephelus; Epinephelidae) from the Indo-Pacific. Copeia; 104 (3): 658-662. 